\title{
Does the Success of Information Systems Really Matters to Firm Performance?
}

\author{
Rich C. Lee ${ }^{1,2}$ \\ ${ }^{1}$ Department of Information Management, National Sun Yat-sen University, Kaohsiung, Chinese Tapei; ${ }^{2}$ System Technology Group, \\ IBM, Chinese Tapei. \\ Email: richchihlee@gmail.com
}

Received February $10^{\text {th }}, 2012$; revised April $1^{\text {st }}$, 2012; accepted April $11^{\text {th }}, 2012$

\begin{abstract}
Many failed listed-enterprises had strong information capabilities and resources; however such advantage did not help these enterprises survive during the economy difficult times. Previous research of DeLone and McLean (D \& M) implied the success of information systems will enhance the performance of enterprises. Based on this implication, many enterprises continuously invested resources on information systems as a strategy trying to gain advantage over competitors. This paper argues the Net Benefits in D \& M model—resulted from the success of Information system—does not always significantly improve the Enterprise Performance but rather has a limit on it. In fact, such an excess investment cannot improve the Enterprise Performance but exhausts more valuable resources instead. The implication of this paper is to encourage enterprises to revisit their valuable service and reevaluate the Socio-Influences before investing more on information systems.
\end{abstract}

Keywords: Information System Success; Firm Performance; Service Science

\section{Introduction}

Information systems have become the backbone of enterprise operations for years. Many information systems highly dependent enterprises address more on reliability and sustainability. Enterprise competitiveness relies on the success of information systems; consequently these systems help enterprises generate more revenue. DeLone and McLean (D \& M) had argued that Information-Quality, System-Quality, and Service-Quality could stimulate Intention-to-Use and User-Satisfaction. The stimulation would further positively influence Net-Benefits [1]. Figure 1 illustrated the updated version of D \& M Information Systems Success model as follows:

Information systems success cannot be achieves without adequate qualified resources. Resource-based view is one of the fundamental theories to analyze the impact of information technology on business performance. The enterprise competitive advantages are determined by the unique valuable resources [2] having the following characteristics: 1) Valuable: the resource is used to conceive or implement strategies that improve efficiency and effectiveness; 2) Rare: the resoursces is not easy to acquire through a short period of time by competitors; 3) Imperfectly Imitable: the resource is not easy to replicate or to imitate owing to its unique historical social inevitable conditions; and 4) Non-Substitutable: The resource is not easily replaceable. Figure 2 illustrated that Enterprise Performance would be influenced by its valuable re sources

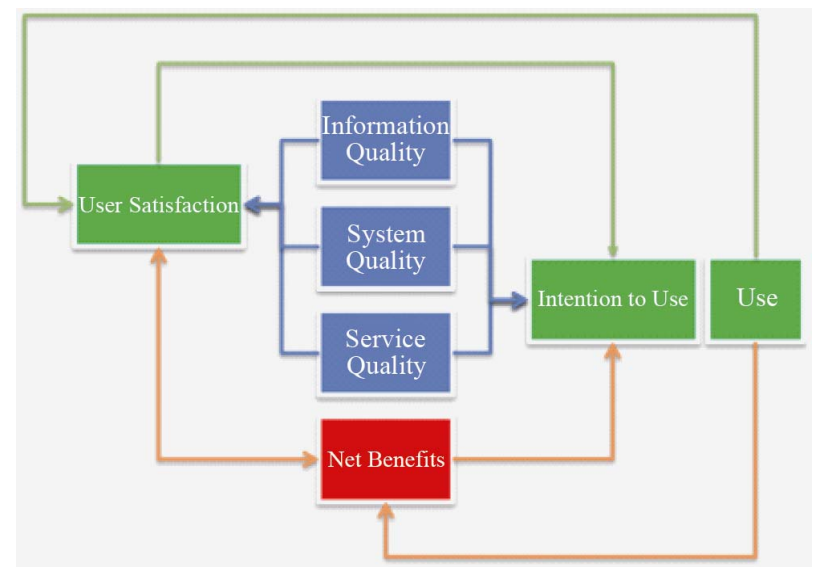

Figure 1. D \& M Information systems success updated model.



Figure 2. Resource-based view information system performance model. 
through Information Management Capabilities.

The Information Management Capabilities influence the Enterprise Performance though three important organizational capabilities: 1) customer, 2) process, and 3) performance management capability [3]. While the enterprise performance can be measured by various results: 1) customer-focused, 2) financial, 3) human resource, and 4) organization effectiveness. Figure 3 illustrated that Enterprise Performance would be influenced by its Information Management Capabilities through three mediators_organizational capabilities.

However, Enterprise Performance is a perceived outcome of effective Information Management Capabilities. It does not always reflect to the real business situation. Business situation is detersmined by many none technological factors such as economy growth, government regulations, and competitors movement. It will be reflected on the outcome of business activities-Actual Enterprise Performance-reported by enterprise financial statements. Several measurements are commonly used in evaluating Actual Enterprise Performance [4-6]:

- Return on Assets (ROA): It is the ratio of Net Income from Income Statement divided by Total Assets from Balance Sheet. ROA reflects the ability of a company to utilize its assets to gain a net profit. Net Income is the amount earned by a company after subtracting out the expenses incurred, including depreciation and taxes.

- Return on Equity (ROE): It is the ratio of Net Income from Income Statement divided by EquityAssets minus Liabilities - from Balance Sheet. ROE reflects the efficiency of a company to spend the investment to gain a net profit.

- Tobin's Q Rate: It is the ratio of market value of a company's assets divided by their replacement value. In common financial practice, the ratio can be calcu-

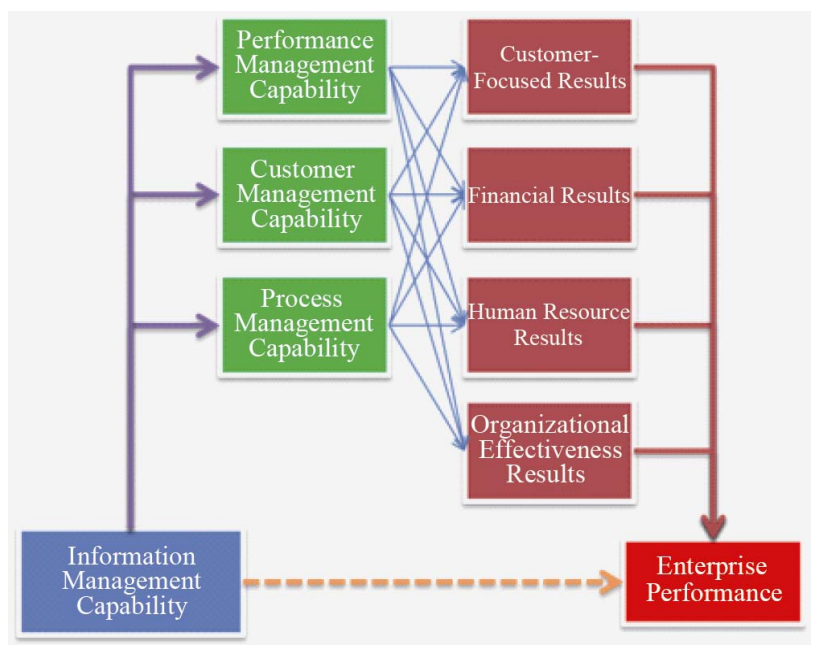

Figure 3. Information management capabilities performance model. lated by: (Equity Market Value + Liability Book Value)/ (Equity Book Value + Liability Book Value). The company with high ratiocan spend more on exploring new initiatives. This paper used Operating Profit Margin (OPM) as Tobin's Q for simplicity.

However, each enterprise plays the roles either supplier or consumer, or both, in the value chain which is an ecosystem with competition. Thus there should be a gap between Perceived and Actual Enterprise Performance due to both external and internal Socio-Influences such as organizational, competitiveness, and economy situation [7]. Such Socio-Influences may root from: 1) technology leadership - gap needs to overcome, 2) component challenge-necessity within the ecosystem, 3) complement challenge - alternatives being replaced, 4) vertical integration-repositioning in the ecosystem, and 5) technology maturity - the competitor could easily replicate the technology [8]. Therefore, the Socio-Influences could be the factors that depress the outcome from Perceived to Actual Enterprise Performance; in other words, more improvement or investment on information systems might not significantly enhance Actual Enterprise Performance at all.

This paper re-examined D \& M information systems success model, resource-based view capabilities of information management, and financial measurement of Enterprise Performance, hypothesized that Socio Influences are the gap between Perceived and Actual Enterprise Performance. This paper also argued that when information systems become mature to industry, conesquently, they are not valuable resources anymore; the Net Benefits will become a constant to Enterprise Performance; it means more investment on information systems will not produce significant Enterprise Performance any more. In fact, even there is no information system in present; the enterprise will still possess a minimal Enterprise Performance through manual processing.

\section{Research Method}

Figure 4 illustrated the proposed Enterprise Performance Gap model which consists three major parts: 1) Information Management Capabilities; 2) Perceived Enterprise Performance; and 3) Actual Enterprise Performance. This paper posited the Socio Influences moderating between actual and perceived Enterprise Performance; three management capabilities namely performance, customer, and process mediating between Information Management Capabilities and perceived Enterprise Performance; and Information Management Capabilities are positively influenced by D \& M three quailities information, system, and service respectively.

\subsection{Hypotheses}

The hypotheses are described in regression formulae 


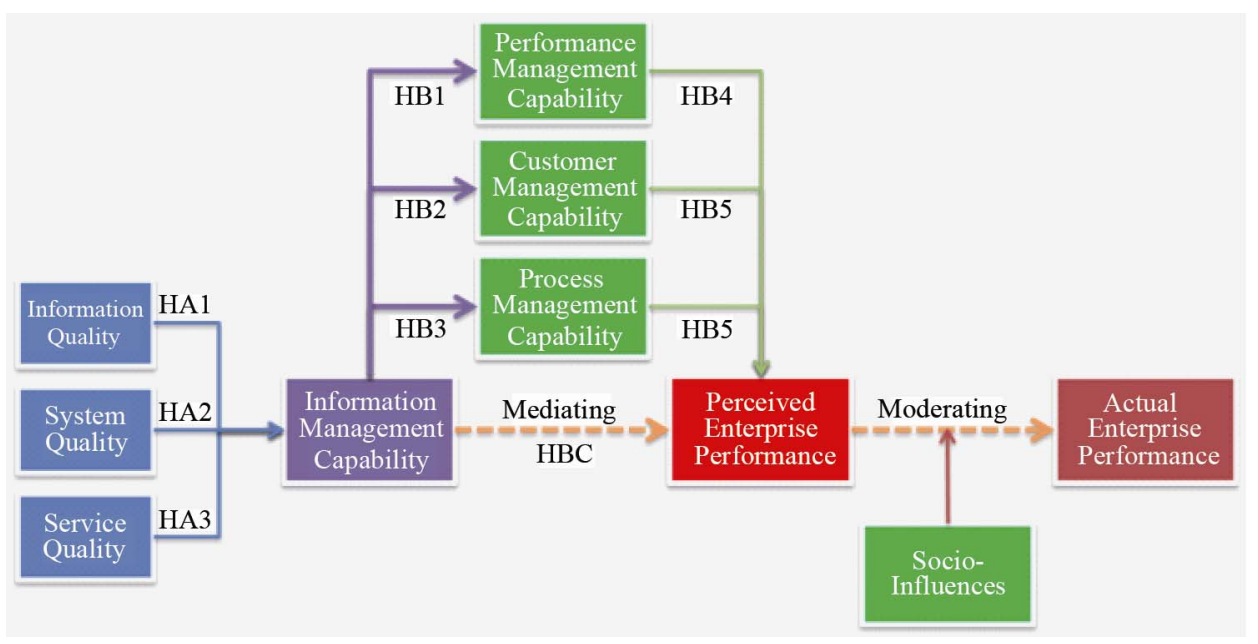

Figure 4. Enterprise Performance Gap model.

which are expected to be significant as follows:

- Information Management Capabilities (HA1, HA2, and HA3 shown in Figure 4):

The resources and capabilities of information systems interlink with their utilization, organizational performance and business value [9]. While the capabilities of information systems are measured by their qualities contributed, therefore, Information Management Capabilities are positively influenced by three qualities namely Information, System, and Service [3]. Formula 1 depicts the linear regression as follows, and $\beta_{1}, \beta_{2}$, and $\beta_{3}$ are expected to be significant:

Information Management Capabilities $=\beta_{0}+\beta_{1}$

$\times$ Information Quality $+\beta_{2} \times$ System Quality

$+\beta_{3} \times$ Service Quality $+\varepsilon$

- Mediation of Management Capabilities (HB1, HB2, and HB3 shown in Figure 4):

Information management capability enables valuable organizational capabilities through these three important organizational capabilities which mediating the links between information management capability and several measures of firm performance [3]. Performance, Customer, and Process Management Capacities are positively influenced by Information Management Capabilities respectively. Formulas (2-1), (2-2), and (2-3) depict the linear regression as follows, and $\beta_{1}$ and $\beta_{2}$ are expected to be significant:

$$
\begin{aligned}
& \text { Performance Management Capacity }=\beta_{0}+\beta_{1} \\
& \quad \times \text { Information Management Capabilities }+\varepsilon \\
& \text { Customer Management Capacity }=\beta_{0}+\beta_{1} \\
& \quad \times \text { Information Management Capabilities }+\varepsilon
\end{aligned}
$$

$$
\begin{aligned}
& \text { Process Management Capacity }=\beta_{0}+\beta_{1} \\
& \quad \times \text { Information Management Capabilities }+\varepsilon
\end{aligned}
$$

- Mediation of Perceived Enterprise Performance (HB4, HB5, and HB6 shown in Figure 4):

Well-developed IT infrastructures give rise to superior information management capability that plays a role in facilitating development of important customer management, process management, and performance management capabilities, and further more, reaches superior firm performance [3]. Perceived Enterprise Performance is positively influenced by Performance, Customer, and Process Management Capacity respectively. Formula 3 depicts the linear regression as follows; $\beta_{1}, \beta_{2}$, and $\beta_{3}$ are expected to be significant respectively:

Perceived Enterprise Performance $=\beta_{0}+\beta_{1}$

$$
\begin{aligned}
& \times \text { Performance Management Capacity }+\beta_{2} \\
& \times \text { Customer Management Capacity }+\beta_{3} \\
& \times \text { Process Management Capacity }+\varepsilon
\end{aligned}
$$

\section{- Moderation of Actual Enterprise Performance (HC1} and HC2 shown in Figure 4):

Information systems have impacts on social, economy, organization, and the way of management, but also are mutated under the influences from them [9]. Socio Influences are positively influenced by Perceived Enterprise Performance; and Actual Enterprise Performance is positively influenced by Socio Influences as well. Formula 4 depicts the moderation regression as follows; $\beta_{1}, \beta_{2}$, and $\beta_{3}$ are expected to be significant respectively:

The hypotheses are described in regression formulae which are expected not to be significant as follows (HBC and HCD shown in Figure 4):

Actual Enterprise Performance $=\beta_{0}+\beta_{1} \times$ Perceived Enterprise Performance $+\beta_{2} \times$ Socio Influences $+\beta_{3}$

$\times($ Perceived Enterprise Performance $\times$ Socio Influences $)+\varepsilon$ 
When above mentioned Mediation effects (Management Capabilities and Enterprise Performance) are positive, the linear regression depicted by Formulas $\mathbf{5}$ and $\mathbf{6}$ should not be significant (i.e. both $\beta_{1}$ are not expected to be significant respectively).

$$
\begin{aligned}
& \text { Perceived Enterprise Performance }=\beta_{0}+\beta_{1} \\
& \quad \times \text { Information Management Capabilities }+\varepsilon \\
& \text { Actual Enterprise Performance }=\beta_{0}+\beta_{1} \\
& \quad \times \text { Perceived Enterprise Performance }+\varepsilon
\end{aligned}
$$

\section{- S-Shape Correlation between Perceived and Actual Enterprise Performance:}

Formulas (7-1) and (7-2) demonstrates a theoretical model in $S$-shape illustrated in Figure 5 about the ideal correlation between actual and perceived Enterprise Performance. The coefficient $\rho$ represents how significant Perceived Enterprise Performance shall influence on Actual Enterprise Performance; $\gamma$ represents the minimal Actual Enterprise Performance without information systems; and $\varepsilon$ represents the phase that information systems have not produced significant perceived Enterprise Performance yet.

$$
\begin{aligned}
& \text { Let } \quad x=\text { Performance }_{\text {perceived }}-\epsilon \\
& \text { Performance }_{\text {actual }}=\rho \times e^{x} /\left(1+e^{x}\right) \rho+\gamma
\end{aligned}
$$

\subsection{Variables}

Information Quality: The desirable characteristics of the system outputs including: relevance, understandability, accuracy, conciseness, completeness, understandability, currency, timeliness, and usability [10].

System Quality: The desirable characteristics of an information system, such as: ease of use, system flexibility, system reliability, and ease of learning, as well as system features of intuitiveness, sophistication, flexibility, and

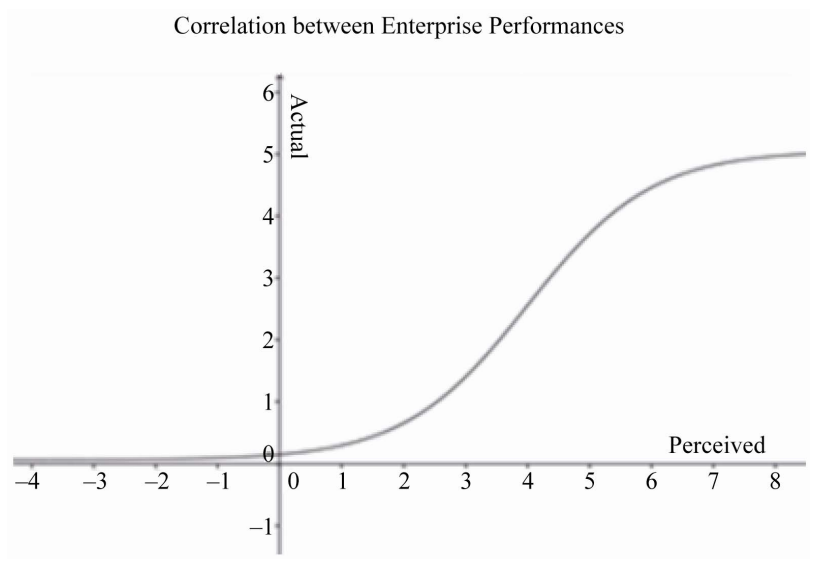

Figure 5. S-shape between Perceived and Actual Enterprise Performances. response times [10].

Service Quality: The quality of the support that system users receive from the IS department and IT support personnel, such as: responsiveness, accuracy, reliability, technical competence, and empathy of the personnel staff [10].

Information Management Capabilities: The ability to 1) provide data and information to users with the appropriate levels of accuracy, timeliness, reliability, security, and confidentiality; 2) provide universal connectivity and access with adequate reach and range; and 3) tailor the infrastructure to emerging business needs and directions [3].

Performance Management Capacity: The ability to design and manage an effective performance measurement and analysis system, including selection of appropriate metrics, gathering of data from appropriate sources of performance, analysis of data to support managerial decision making, communication of performance to appropriate stakeholders, and alignment of the performance management system with current and future business needs and directions [3].

Customer Management Capacity: The ability to determine the requirements, expectations, and preferences of its customers and markets and is of significant importance in the contemporary business environment marked by hyper-competition [3].

Process Management Capacity: The ability to attain flexibility, speed, and cost economy through the design and management of three major types of processes: 1) product design and delivery processes, including new product development and manufacturing; 2) non-product and non-service business growth processes, including innovation, research and development, supply chain management, supplier partnering, outsourcing, mergers and acquisitions, global expansion, and project management; and 3) support processes, such as finance and accounting, facilities management, and human resources management. [3].

Perceived Enterprise Performance: An equivalent of D \& M Net Benefits. The extent to which IS are contributing to the success of individuals, groups, organizations, industries, and nations, such as: improved decision-making, improved productivity, increased sales, cost reductions, improved profits, market efficiency, consumer welfare, creation of jobs, and economic development [10].

Socio-Influences: Both external and internal influences. The external influence is about social, political, economic and technological factors; the internal influence is about organizational structure, strategies, and goals [7].

Actual Enterprise Performance: The financial indicators derived from enterprise financial reports including ROA, ROE, and Tobin's Q Rate [4-6]. 


\subsection{Sample}

According to Semiconductor Equipment and Materials International (SEMI), Taiwan has been poised to overtake Japan in 2011 as the world's largest semiconductor materials market with growth rate of 36.2\% from 2009 . The semiconductor production depends on the success of manufacturing execution systems (MES) intensively. Financial institute operations rely on service and risk management systems to comply with the regulations and to maximize the revenue as well. The information management capabilities of these industries are considered mature than other general business. This paper collected two types of data, the empirical data from Taiwan publiclisted companies of these two sectors, and the actual Enterprise Performance data from Taiwan Economy Journal (TEJ). TEJ has been widely used in technology and finance related researches on Taiwan issues [11,12].

The survey questionnaires were collected from department managers related to IS, finance, manufacturing, customer-care, and auditing. It also asked the surveyed managers to focus on their core information systems including: 1) customer relationship management system; 2) supply-chain or vendor management system; 3) manufacturing execution system for semiconductor, core-banking system for banks, trading system for securities, and policy system for insurance respectively.

\subsection{Encoding and Data Set}

The sample frame covered the numbers of surveyed enterprises across sectors: 1) sixty-eight for semiconductor; 2) thirty-fivefor finance; and 3) seventy for optoelectronic industries respectively. The response rate was $45 \%$ for the first round, $35 \%$ for the second round, and $11 \%$ for the third round, $91 \%$ in total.

In order to facilitate the analysis efficiently, this paper used the same company security codes as Taiwan Stock Market designated for the surveyed enterprises, and used abbreviations for different sectors and departments as well (see Appendix 1). The schema of data set covered: 1) respondent profile; 2) qualities; 3) capabilities; 4) socioinfluences; and 5) performances as hypotheses suggested (see Appendix 2).

\subsection{Procedure}

Companies were contacted through a multi-staged procedure. First, a contact list derived from TEJ was used to control and monitor the progress of data collection (see Appendix 3). Secondly, a survey web site was prepared to facilitate the data collection process; the participants can find resources about the survey. Thirdly, a series of telephone calls were made to verify the contact information about managers of each company on the list, and briefly described the would be a survey kindly requiring their responses. Fourthly, a cover letter of explaining the purpose the survey, how the expected research results would benefit to their companies, and the survey (see Appendix 4) was emailed to the listed managers. Fifthly, a second-round telephone calls were made to thank to those already-responded managers and to remind those who had not responded yet. A gift was sent to each responded-manager through the first line sales or business partners of the author's company. Finally, all responded data were imported to a database for further statistical analysis and tests.

The factors of Actual Enterprise Performance were derived from financial reports instead of from perception. These factors were clustered into five groups as Likerttype scales applying $k$-means algorithm which has been widely used in financial profitability prediction [13,14]. Actual Enterprise Performance for each enterprise was calculated as Formula 8. The weights of $\alpha, \beta$ and $\gamma$ are 1 as default value but also are sector dependent. For example, For those semiconductor enterprises, their operations rely on equipment intensively, thus the weight for ROE shall be assigned greater value than 1.For finance enterprises, the weight for OPM can be assigned greater value than 1 to emphasize the importance on operation cost.

$$
\begin{aligned}
& \text { Actual Enterprise Performance } \\
= & \sqrt[3]{(\alpha \cdot O P M)(\beta \cdot R O E)(\gamma \cdot R O A)}
\end{aligned}
$$

\subsection{Statistical Analysis}

- Multi-Trait/Multi-Method Analysis: To analyze the Convergent and Discriminant Validity, estimate the degree of method specificity, and scrutinize the generalizability of results of empirical studies and assessment procedures across methods [15].

- Multivariate Analysis of Variance (MANOVA): To check whether there are differences among semiconductor, optoelectronic and finance sectors on Qualities, Management Capabilities, Enterprise Performances, and Socio Influences respectively.

- Linear Regressions: To see if there were significant correlations against hypotheses under 95\% confidence level. Also to validate the mediating and moderating effects of Management Capabilities and Socio Influences respectively.

- Ordinary Least Squares (OLS) Regression Fitting: To check the correlation between Perceived and Actual Enterprise Performances fits $S$-shaped curve. The cost prediction in business behaves as an $S$-shaped curve requiring better regression than the usual linear regression [16]. The behavior of Enterprise Performances is very similar to that concept and expected to be $S$-shaped as well. 
- Clustering Analysis: Using k-means to check there were significant differences for: 1) Perceived and Actual Enterprise Performances; and 2) Socio-Influences within the sector and across sectors as well [17].

\section{Discussion}

This paper revalidated the robustness of models of D\&M Information Systems Success, Resource-based View Information System Performance, and Information Management Capabilities Performance as well. It also presents a composite model—Enterprise Performance Gap Model - to articulate the depression effect of Perceived Enterprise Performance by Socio Influences reflected through financial measurements.

The process of information technology adoption and its use over time- -before and after adoption-is critical to measure the benefits of the adoption [18]. Enterprises with similar business model entered the market at different timing. This influences the maturity of information technology adoption. Latter entrants will certainly adopt newer technologies than their predecessors. Evidence showed that in high-tech industries the newer technology adoption is faster than ever due to globalization [19]. The predecessors will also enhance or update their information systems to maintain the competitiveness. The assumption behind this is that the continuous investment on information systems will be expected to gain positive competitiveness in the market. As a matter of fact, the reason why information systems improve productivity is through internal process optimization-management capabilities; otherwise it will be just another example of productivity-paradox [20]. The investment decision-making process of information systems keenly varies by different IT governance patterns [21]. This makes more obscure that the investment should be based on the outcome of Actual Enterprise Performance. When business model becomes mature, the difference of Management Capabilities between competitors is not significant anymore, thus Socio Influences will dominate the behavior of business performance.

For emerging technologies such as optoelectronic industry, the behavior of Enterprise Performance attributed to technology investment agrees to S-shaped curve: slow initial, accelerated, then diminishing improvement [22]. Another similar technology diffusion growth which followed $S$-curve is mobile telephony [23]. For those less information systems dependent companies than high-tech industries, the $S$-shape will be flatter (coefficient $\rho$ in Formula 7-2 is smaller relatively) because the investment on information systems is not so sensitive as those technology-dependent companies. This coincides to what the paper has posited.

\section{Conclusion}

This paper re-examined D \& M information systems success model, resource-based view capabilities of information management, and financial measurement of enterprise performance, posited that Socio Influences are the gap between Perceived and Actual Enterprise Performance. It also validated that the information technology diffusion does have a limit unless newer valuable services are brought out to their customers. These newer valuable services will alleviate the impact from Socio Influences. Otherwise the Perceived Enterprise Performance contributed by information systems will be depressed; the Actual Enterprise Performance will behave as a near-constant just as the right-upper part of an $S$-shaped curve. The $S$-shaped curve can be used to gain insight about the relative payoff of investment in competing technologies, as well as to provide more insights about when and why some technologies overtake others in the race for dominance as explained earlier. The implication of this finding is to encourage enterprises to revisit their valuable services, to gain better market position, and to reevaluate the Socio Influences before investing more on information systems.

\section{REFERENCES}

[1] W. H. Delone and E. R. McLean, "The DeLone and McLean Model of Information Systems Success: A TenYear Update," Journal of Management Information Systems, Vol. 19, No. 4, 2003, pp. 9-30.

[2] T. P. Liang and J. You, "Resource-Based View in Information Systems Research: A Meta-Analysis,” Proceedings of Pacific Asia Conference on Information Systems, Hyderabad, 10-12 July 2009, p. 72.

[3] S. Mithas, N. Ramasubbu and V. Sambamurthy, "How Information Management Capability Influences Firm Performance," Management Information Systems Quarterly, Vol. 35, No. 1, 2011, pp. 237-256.

[4] N. A. Morgan, D. W. Vorhies and C. H. Mason, "Market Orientation, Marketing Capabilities, and Firm Performance," Strategic Management Journal, Vol. 30, No. 8, 2009, pp. 909-920.

[5] E. Brynjolfsson, L. Hitt and H. Kim, "Strength in Numbers: How Does Data-Driven Decisionmaking Affect Firm Performance?” 2011. http://ssrn.com/abstract=1819486

[6] L. Bebchuk, A. Cohen and A. Ferrell, "What Matters in Corporate Governance?” Review of Financial Studies, Vol. 22, No. 2, 2009, pp. 783-827. doi:10.1093/rfs/hhn099

[7] R. Stockdale and C. Standing, "An Interpretive Approach to Evaluating Information Systems: A Content, Context, Process Framework,” European Journal of Operational Research, Vol. 173, No. 3, 2006, pp. 1090-1102. doi:10.1016/j.ejor.2005.07.006

[8] R. Adner and R. Kapoor, "Value Creation in Innovation Ecosystems: How the Structure of Technological Interdependence Affects Firm Performance in New Technol- 
ogy Generations," Strategic Management Journal, Vol. 31, No. 3, 2010, pp. 306-333. doi:10.1002/smj.821

[9] A. Borek, M. Helfert, M. Ge and A. K. Parlikad, “An Information Oriented Framework for Relating IS/IT Resources and Business Value," Proceedings of the International Conference on Enterprise Information Systems, Beijing, 8-11 June 2011, pp. 358-367.

[10] S. Petter, W. DeLone and E. McLean, "Measuring Information Systems Success: Models, Dimensions, Measures, and Interrelationships," European Journal of Information Systems, Vol. 17, No. 3, 2008, pp. 236-263. doi:10.1057/ejis.2008.15

[11] W. Y. Wang and C. Chang, "Intellectual Capital and Performance in Causal Models: Evidence from the Information Technology Industry in Taiwan,” Journal of Intellectual Capital, Vol. 6, No. 2, 2005, pp. 222-236. doi:10.1108/14691930510592816

[12] S. M. L. Wong, S. Opper and R. Hu, "Shareholding Structure, Depoliticization and Firm Performance," Economics of Transition, Vol. 12, No. 1, 2004, pp. 29-66. doi:10.1111/j.0967-0750.2004.00171.x

[13] S. A. Ionescu, C. S. Murgoci, C. M. Gheorghe and E. Ionescu, "Making Predictions of the Profitability on the Financial Markets Using Discriminant Analysis," Recent Advances in Artificial Inteligence, Knowledge Engineering and Data Bases, 2009, p. 495.

[14] S. A. Ionescu, C. S. Murgoci, C. M. Gheorghe and E. Ionescu, "Towards Profitability on the Financial Markets: A Discriminant Analysis Approach,” WSEAS Transactions on Business and Economics, Vol. 6, No. 3, 2009, pp. 99-111.

[15] M. Eid, C. Geiser and F. W. Nussbeck, "Multitrait-Multimethod Analysis in Psychotherapy Research: New Methodological Approaches,” Psychotherapy Research, Vol. 19, No. 4-5, 2009, pp. 390-396. doi:10.1080/10503300802621198

[16] O. A. Isaac, A. A. Adedeji and I. R. Ismail, "Polynomial
Regression Model of Making Cost Prediction in Mixed Cost Analysis," Mathematical Theory and Modeling, Vol. 2, No. 2, 2012, pp. 14-23.

[17] T. Kanungo, D. M. Mount, N. S. Netanyahu, C. D. Piatko, R. Silverman and A. Y. Wu, "An Efficient K-Means Clustering Algorithm: Analysis and Implementation," IEEE Transactions on Pattern Analysis and Machine Intelligence, Vol. 24, No. 7, 2002, pp. 881-892.

[18] E. Karahanna, D. W. Straub and N. L. Chervany, "Information Technology Adoption across Time: A Cross-Sectional Comparison of Pre-Adoption and Post-Adoption Beliefs,” Management Information Systems Quarterly, Vol. 23, No. 2, 1999, pp. 183-213. doi:10.2307/249751

[19] D. Comin and B. Hobija, “An Exploration of Technology Diffusion,” The American Economic Review, Vol. 100, No. 5, 2010, pp. 2031-2059.

[20] V. Grover, J. Teng, A. H. Segars and K. Fiedler, “The Influence of Information Technology Diffusion and Business Process Change on Perceived Productivity: The IS Executive's Perspective,” Information \& Management, Vol. 34, No. 3, 1998, pp. 141-159. doi:10.1016/S0378-7206(98)00054-8

[21] Y. Xue, H. Liang and W. R. Boulton, "Information Technology Governance in Information Technology Investment Decision Processes: The Impact of Investment Characteristics, External Environment, and Internal Context," Management Information Systems Quarterly, Vol. 32, No. 1, 2008, p. 67.

[22] M. A. Schilling and M. Esmundo, “Technology S-Curves in Renewable Energy Alternatives: Analysis and Implications for Industry and Government,” Energy Policy, Vol. 37, No. 5, 2009, pp. 1767-1781. doi:10.1016/j.enpol.2009.01.004

[23] F. S. Wu and W. L. Chu, "Diffusion Models of Mobile Telephony,” Journal of Business Research, Vol. 63, No. 5, 2010, pp. 497-501. 


\section{Appendices}

\section{Appendix 1. Abbreviations for Data.}

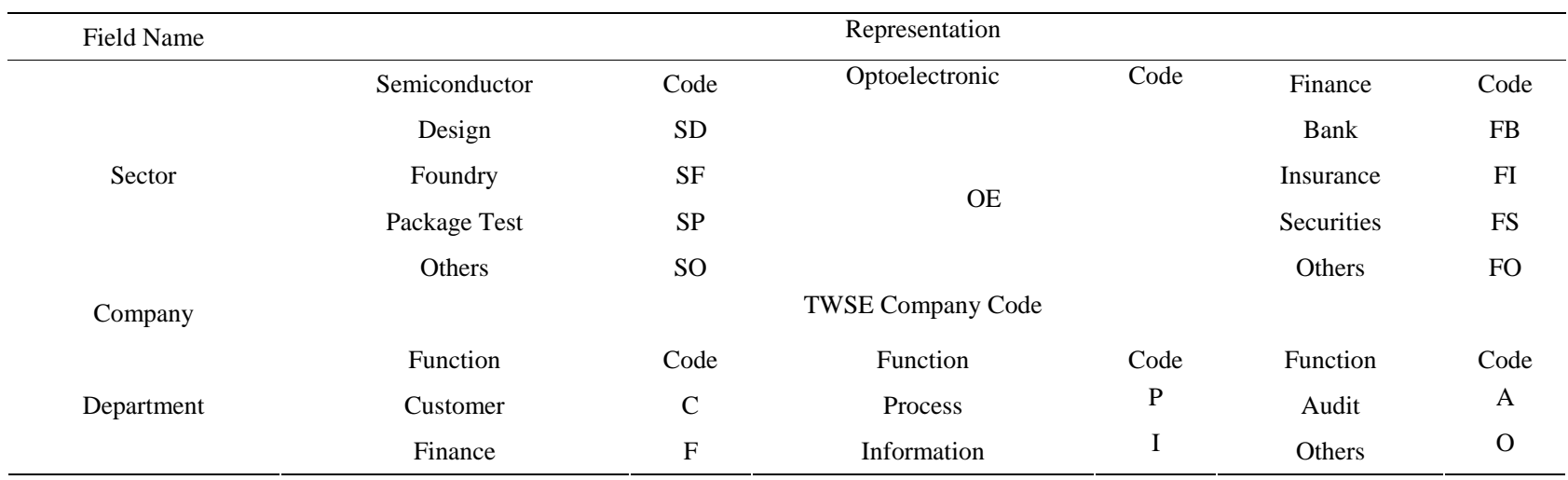

\section{Appendix 2. Data Set Schema.}

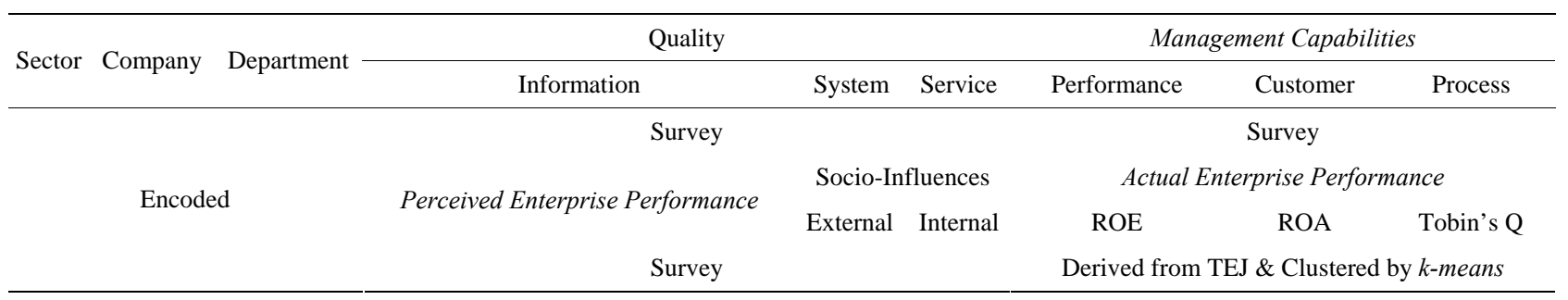

\section{Appendix 3. Survey Progress Control Table (Sample).}

\begin{tabular}{|c|c|c|c|c|c|c|c|c|c|c|c|}
\hline \multirow{2}{*}{ Company } & \multicolumn{4}{|c|}{ Manager } & \multicolumn{3}{|c|}{ Time of Calls } & \multicolumn{3}{|c|}{ Response of Calls } & \multirow{2}{*}{ Operato } \\
\hline & Position & Name & TEL & Email & $1 \mathrm{st}$ & 2nd & 3rd & $1 \mathrm{st}$ & 2nd & Gift & \\
\hline \multirow{6}{*}{ TWSE Company Code } & Customer & $\mathrm{C}$ & & & & & & & & $\mathrm{N} / \mathrm{Y}$ & \\
\hline & Finance & $\mathrm{F}$ & & & & & & & & & \\
\hline & Process & $\mathrm{P}$ & & & & & & & & & \\
\hline & Information & I & & & & & & & & & \\
\hline & Audit & A & & & & & & & & & \\
\hline & Others & $\mathrm{O}$ & & & & & & & & & \\
\hline
\end{tabular}

\section{Appendix 4. Questionnaire.}

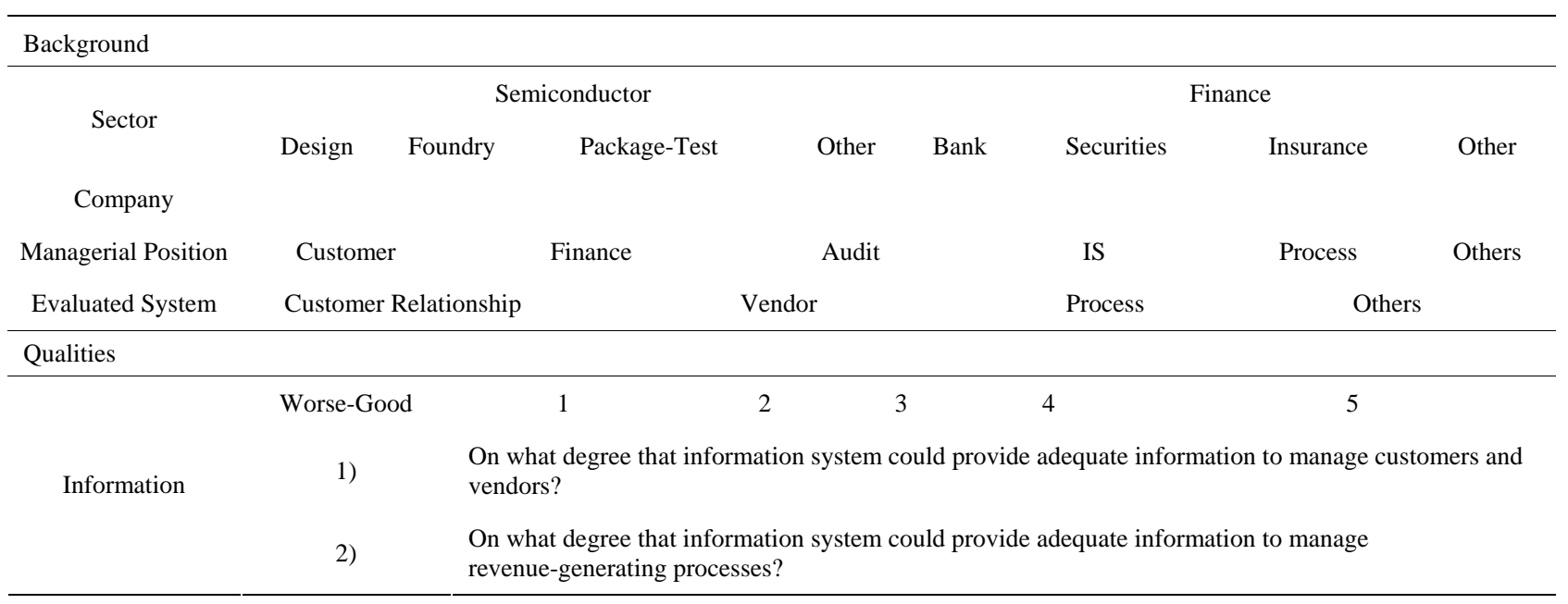




\section{Continued}




Appendix 5. Actual Enterprise Performance (Semiconductor 2011 Q3 Sample).

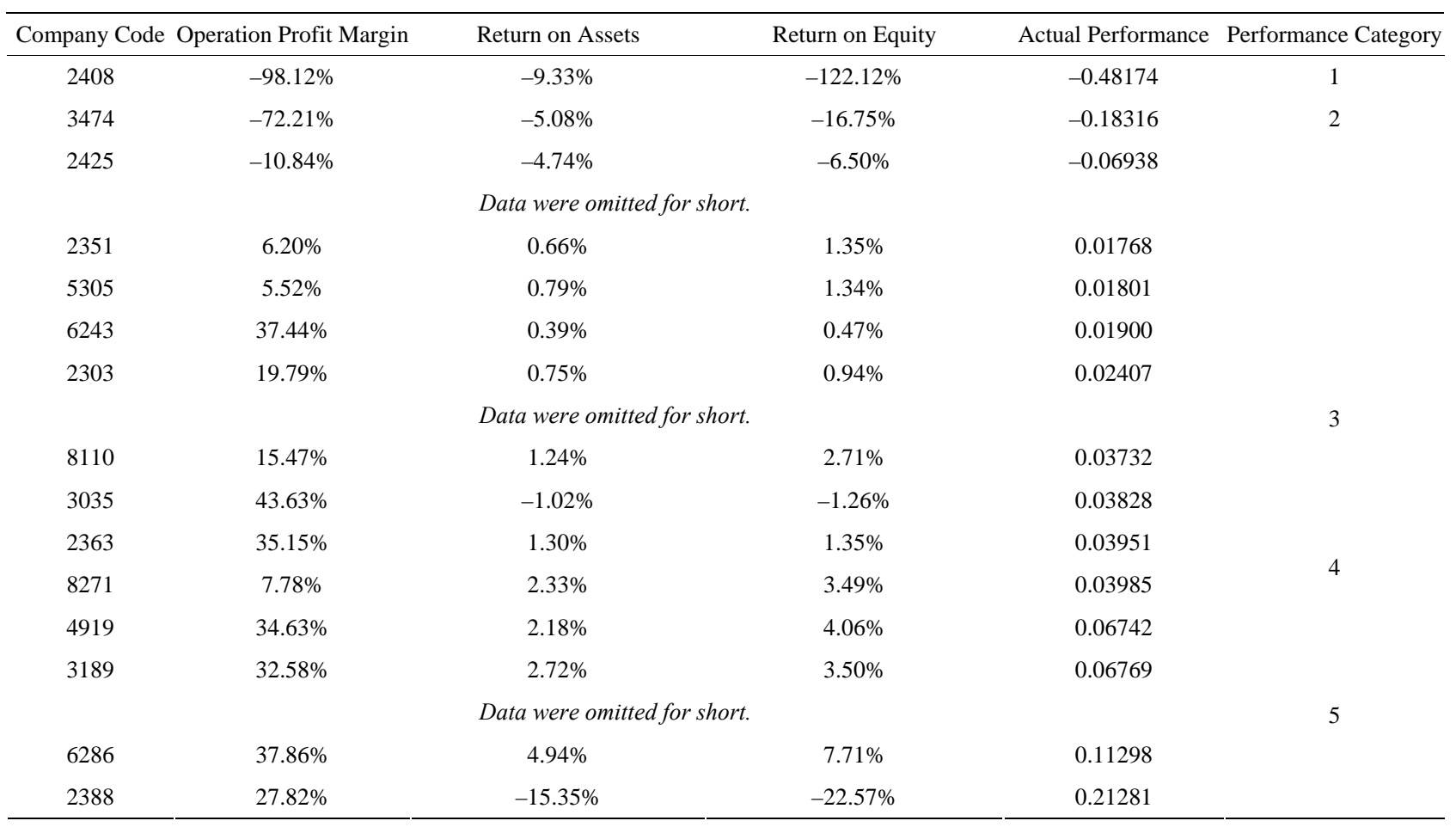

